\title{
Case report of a neonate with ocular toxoplasmosis due to congenital infection: estimation of the percentage of ocular toxoplasmosis in Greece caused by congenital or acquired infection
}

This article was published in the following Dove Press journal:

Clinical Ophthalmology

20 November 2013

Number of times this article has been viewed

\author{
loannis Asproudis' \\ loannis Koumpoulis' \\ Chris Kalogeropoulos' \\ Georgios Sotiropoulos' \\ Margarita Papassava ${ }^{2}$ \\ Miltiadis Aspiotis' \\ 'Department of Ophthalmology, \\ Medical School, University of \\ loannina, ${ }^{2}$ Neonatal Intensive Care \\ Unit, University Hospital of loannina, \\ loannina, Greece
}

\begin{abstract}
We report a case of a newborn male child with congenital toxoplasmosis. During pregnancy seroconversion occurred and positive titers of antitoxoplasmic antibodies (immunoglobulin $\mathrm{M}$ and $\mathrm{G}$ ) were found in the mother, in the third trimester. She received treatment with spiramycin. After birth, the neonate presented with chorioretinitis and intracranial calcifications. The neonate received treatment with pyrimethamine, sulfadiazine, and leucovorin for 1 year. In addition to using a previously described method, we report for the first time in Greece an estimation regarding the percentage of ocular toxoplasmosis caused by congenital or acquired infection. We estimate that ocular toxoplasmosis in Greece is caused in $7 \%$ of the cases by congenital infection, and in $93 \%$ of the cases by acquired infection.
\end{abstract}

Keywords: toxoplasmosis, ocular, congenital, acquired, chorioretinitis

\section{Introduction}

Toxoplasmosis is one of the most common parasitic infections in humans, and infects up to one-third of the world's population. ${ }^{1}$ Infection mainly occurs through eating raw or undercooked meat that contains tissue cysts of Toxoplasma gondii or by eating food or drinking water that is contaminated with oocysts of $T$. gondii spread by cats. The course of infection is usually benign and asymptomatic in immunocompetent individuals. In some patients, toxoplasmosis may present with lymphadenopathy or chorioretinitis. An infection acquired during pregnancy can be transmitted transplacentally and cause severe abnormalities to the developing fetus. ${ }^{1}$ In this article, we present the case of a newborn with congenital toxoplasmosis and review the epidemiological data regarding congenital toxoplasmosis in Greece.

\section{Case report}

We report a case of a newborn male child who was referred to the Neonatal Intensive Care Unit of the University Hospital of Ioannina, Greece, 22 hours after birth because of a temperature of $37.6^{\circ} \mathrm{C}$ and positive C-reactive protein (CRP) of $30.3 \mathrm{mg} / \mathrm{L}$ at partum. The gestational age was 39 weeks, and the birth weight was 3,190 g. He was delivered vaginally, with a probable high rupture of the membranes $18-24$ hours prepartum. Amniotic
Correspondence: loannis Asproudis Department of Ophthalmology, Medical School, University of loannina, Stavros Niarchos Avenue, loannina 45500, Greece

Tel +30 265I 099657

Email asproudisi@yahoo.gr 
fluid was meconium-stained. During pregnancy, seroconversion occurred, and positive titers of antitoxoplasmic antibodies (immunoglobulin [Ig]-M 10.55 index and IgG 799.8 IU/mL) were found during the third trimester. The pregnant woman was treated with spiramycin orally. The neonate was $50 \mathrm{~cm}$ in length, with a head circumference of $34 \mathrm{~cm}$, a good general state, and normal reflexes. The neonate and the mother had the same blood type $\left(\mathrm{A} \mathrm{Rh}^{+}\right)$. Laboratory examinations showed: white blood cell count $18,340 / \mathrm{mm}^{3}$, hemoglobin $16.5 \mathrm{~g} / \mathrm{dL}$, hematocrit $48.8 \%$, platelets $177,000 / \mathrm{mm}^{3}$, CRP $59 \mathrm{mg} / \mathrm{L}$, and negative blood cultures. Temperature remained within normal limits. An early neonatal infection was diagnosed, and the neonate was initially treated with a therapeutic scheme of intravenous amoxicillin and amikacin, followed 4 days later by intravenous gentamicin ( 5 days), cefoxitin ( 8 days), and metronidazole (5 days), due to abdominal distention (necrotizing enterocolitis, stage I). The neonate had high positive titers of $\operatorname{IgG}(2,730 \mathrm{IU} / \mathrm{mL})$ and negative IgM antibodies for T. gondii. Brain ultrasound revealed intracranial calcifications, and ocular examination revealed chorioretinitis in the left eye (Figure 1). Congenital toxoplasmosis was diagnosed, and treatment was started with pyrimethamine, sulfadiazine, and leucovorin for 1 year. Serology for other congenital infections was negative.

\section{Discussion}

Maternal infection with T. gondii during pregnancy or a short time before conception in seronegative women may result

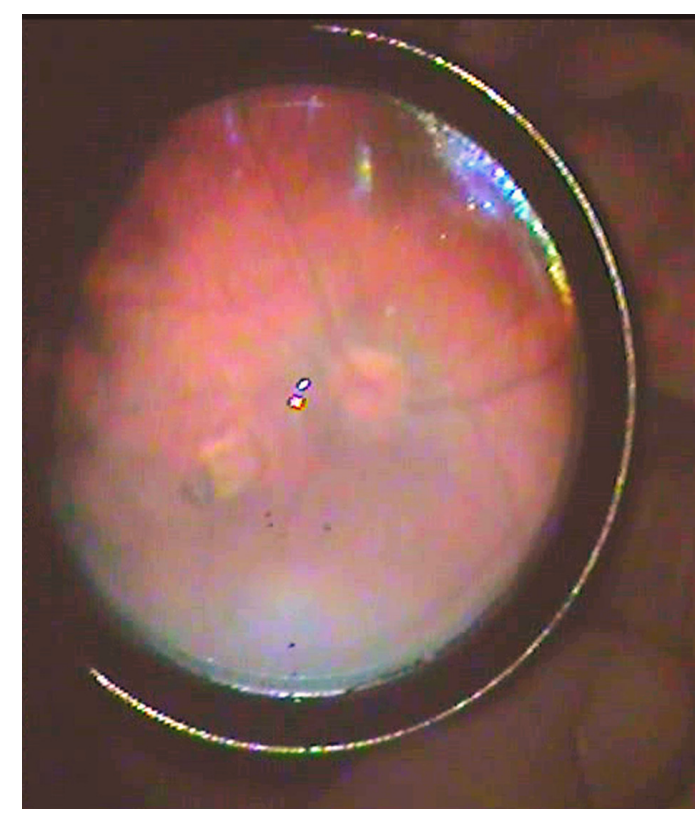

Figure I A chorioretinal scar is observed in the left eye medially to the optic disk. Follow-up visit at the age of 8 months. in transplacental transmission of toxoplasmosis and cause severe abnormalities to the developing fetus. The frequency of vertical transmission of $T$. gondii depends on the time during gestation that the mother acquired the infection. An infection acquired in the first trimester results in a transmission rate of less than $10 \%$, whereas an infection in the third trimester results in a transmission rate greater than $60 \%$. On the other hand, the severity of the congenital disease is greater when early maternal infection occurs. Infection in the first and second trimesters may result in severe congenital toxoplasmosis and cause miscarriage, in utero death, or severe neurologic complications to the fetus. Late maternal infection in the third trimester may cause congenital disease or subclinical infection. The newborns usually have a normal appearance, and the disease may be initially undiagnosed. The newborns may later develop chorioretinitis or neurologic and developmental abnormalities. ${ }^{1}$ If vertical transmission occurs, the newborn with congenital toxoplasmosis in most centers is treated with a combination of pyrimethamine, sulfadiazine, and leucovorin for 1 year. ${ }^{1}$ It should be mentioned, though, that data from the European Multicentre Study on Congenital Toxoplasmosis (EMSCOT) study group found no effect of postnatal treatment on ocular disease, although the power to detect an effect was limited. The effectiveness of postnatal treatment should be evaluated in a large randomized controlled clinical trial. ${ }^{2}$

The treatment of pregnant women that are infected with T. gondii during pregnancy is a controversial issue. Most centers treat infected pregnant women with a spiramycin or pyrimethamine-sulfonamide regimen. ${ }^{1}$ A meta-analysis regarding the effectiveness of prenatal treatment for congenital toxoplasmosis performed by the Systematic Review on Congenital Toxoplasmosis (SYROCOT) study group found weak evidence that prenatal treatment with spiramycin or pyrimethaminesulfonamide significantly reduced the risk of clinical manifestations in infected live-born infants compared with no treatment. ${ }^{3}$ Only a large randomized controlled clinical trial would provide valid evidence of the potential benefit of prenatal treatment. ${ }^{3}$ On the other hand, a report from the EMSCOT study group stated that prenatal treatment within 4 weeks of seroconversion reduced the risk of intracranial lesions compared with no treatment, but there was no significant effect when initiated after 4 weeks. Treatment would likely be most effective when given soon after maternal seroconversion, before the parasite formed bradyzoite cysts that are impenetrable to antibiotics. ${ }^{4}$ On the other hand, there was no consistent relationship between the type or timing of treatment and the risk of ocular lesions. ${ }^{4}$ Another report from the EMSCOT study group stated that 
prenatal treatment substantially reduced the proportion of infected fetuses who developed serious neurological sequelae compared with no treatment. ${ }^{5}$

Cohort studies of children with congenital toxoplasmosis showed that ocular disease, usually chorioretinitis, develops in $17 \%-80 \%$ of them. ${ }^{6-12}$ Earlier studies performed more than 30 years ago reported higher risk of ocular lesions - approximately $80 \% .{ }^{6,7}$ Some of them had a small sample size. These earlier studies were mostly retrospective, and included only referred patients with a symptomatic disease condition, so a selection bias could be present. More recent prospective studies report lower risk of chorioretinitis, ranging from $17 \%$ to $30 \%{ }^{8-12}$ Chorioretinitis mainly occurs before the age of 5 years, ${ }^{2,8}$ but first ocular lesion has been reported as late as 12 years after birth. ${ }^{9}$ These studies confirm an overall good prognosis of congenital toxoplasmosis in Europe and North America. More than $90 \%$ of children with chorioretinitis have normal vision in their best eye, and severe bilateral impairment is rare. ${ }^{10-12}$ In contrast, cohort studies in South America reported more frequent and more severe ocular disease. In the study of Gilbert et al, two-thirds of children with congenital toxoplasmosis in Brazil had eye lesion by 4 years of age, compared with one in six in Europe. ${ }^{13}$ This discrepancy may be due to the predominance of more virulent genotypes of the parasite in South America, which are rarely present in Europe or North America. ${ }^{13}$

In Greece, the seroprevalence of toxoplasmosis in the general population was $37 \%, 29.9 \%$, and $24.1 \%$ in 1984,1994 , and 2004, respectively. ${ }^{14}$ A significant decline in seroprevalence was noticed from decade to decade, possibly explained by the improved socioeconomic situation in Greece. ${ }^{14}$ In studies performed in Greece regarding pregnant women, the seroprevalence rates ranged from $20.1 \%$ to $29.4 \%{ }^{15-17}$ The birth prevalence of congenital toxoplasmosis was 0.51 per 10,000 births for 2009 in Greece. ${ }^{18}$ In other countries involved in the Eurotoxo project, ${ }^{19}$ the birth prevalence of congenital toxoplasmosis was estimated at 7.4 per 10,000 births in Austria, at three per 10,000 births in Denmark, at 13 per 10,000 births in Germany, at 11.3 per 10,000 in Poland, at 0.73 per 10,000 births in Sweden, and at five per 10,000 births in Switzerland..$^{19}$ In 2007, the birth prevalence in France was estimated at 3.3 per 10,000 births. ${ }^{20}$ The birth prevalence in Greece is similar to that reported in Sweden, and much lower than in the other countries involved in the Eurotoxo project. It should be mentioned, though, that the Eurotoxo data were mostly collected before 2000. The estimated lower birth prevalence in Greece compared to those in other countries may reflect the use of different tests and different cutoffs for test positivity, the use of different case definitions and classification systems for congenital toxoplasmosis in each country at the time of the study, and different dietary habits or regional differences in exposure to the parasite. A significant decline was also observed in the last few decades in the seroprevalence of toxoplasmosis in Greece, possibly explained by the improved socioeconomic situation. ${ }^{14}$

Ocular toxoplasmosis, in contrast to what was believed in the past, is mainly caused by acquired infection and not by congenital infection. In Greece, it is estimated that 93\% of cases of ocular toxoplasmosis are caused by acquired infection and $7 \%$ are caused by congenital infection. This estimation is made using the method described by Gilbert and Stanford. ${ }^{21}$ According to Gilbert and Stanford, it is estimated that between $66 \%$ and $86 \%$ of ocular toxoplasmosis is the result of postnatal infection, using epidemiological data from five countries. The lifetime risk of ocular toxoplasmosis because of prenatal infection in Greece is estimated by multiplying the birth prevalence of congenital toxoplasmosis $(0.51 / 10,000)$ by the highest reported estimate $(80 \%)$ of the proportion of congenitally infected children who will eventually present ocular lesions. The lifetime risk of ocular toxoplasmosis because of prenatal infection is approximately $4 / 100,000$. The lifetime risk of ocular toxoplasmosis because of postnatal infection is estimated by multiplying the agespecific prevalence of Toxoplasma infection (using the prevalence in pregnant women in Greece as a proxy measure $[20.1 \%])^{16}$ by the lowest reported estimate of the risk of retinochoroiditis in patients with postnatal toxoplasmosis. Several studies estimate the risk of retinochoroiditis after acquired toxoplasmosis. The lowest reported estimate is $0.3 \%-0.7 \% .^{22}$ According to Perkins, the risk is approximately $2 \%-3 \% .{ }^{23}$ In other studies, the risk is higher. ${ }^{24}$ Using the lowest estimate, $0.3 \%$, the lifetime risk of ocular toxoplasmosis because of postnatal infection is approximately $60 / 100,000$. As a result, it is estimated that $93 \%$ of the cases of ocular toxoplasmosis in Greece are caused by acquired infection. This is the first time that such an estimation regarding ocular toxoplasmosis in Greece is reported. This is a conservative estimate, because we used the highest reported risk $(80 \%)$ for retinochoroiditis following congenital infection and the lowest reported risk $(0.3 \%)$ for retinochoroiditis following acquired infection. We also used the lowest reported prevalence in pregnant women in Greece as a proxy measure $(20.1 \%){ }^{16}$

In order to prevent maternal infection and congenital toxoplasmosis, pregnant women should be informed of the risks of infection with $T$. gondii during pregnancy. They should avoid eating raw or undercooked meat, raw shellfish, 
and unwashed vegetables, and avoid drinking untreated water. The tissue cysts of $T$. gondii can be killed by heating meat. An internal temperature of meat of $56^{\circ} \mathrm{C}$ must be reached for at least 10 minutes. Freezing can also kill the tissue cysts of $T$. gondii. Freezing is needed for at least 2 days at temperatures below $-12{ }^{\circ} \mathrm{C} .{ }^{25}$ Pregnant women should also avoid exposure to litters of kittens.

The incidence of congenital toxoplasmosis in Greece is low, but on the other hand congenital toxoplasmosis can cause potentially severe complications during pregnancy or after birth. Prenatal screening is important in identifying the pregnant women who are infected during pregnancy. These women in most centers receive treatment with spiramycin. Newborns with congenital toxoplasmosis in most centers are treated with pyrimethamine, sulfadiazine, and leucovorin for 1 year in order to have a better prognosis. There is no evidence, though, that prenatal or postnatal treatment has a protective effect on ocular disease. ${ }^{2,3}$ Long-term follow-up is needed for children with congenital toxoplasmosis. The overall functional prognosis of congenital toxoplasmosis in Europe and North America is good. More than 90\% of children with chorioretinitis have normal vision in their best eye, and severe bilateral impairment is rare. ${ }^{10-12}$

\section{Disclosure}

The authors report no conflicts of interest in this work.

\section{References}

1. Montoya JG, Liesenfeld O. Toxoplasmosis. Lancet. 2004;363(9425): 1965-1976.

2. Freeman K, Tan HK, Prusa A, et al. Predictors of retinochoroiditis in children with congenital toxoplasmosis: European, prospective cohort study. Pediatrics. 2008;121(5):e1215-e1222.

3. SYROCOT (Systematic Review on Congenital Toxoplasmosis) study group, Thiébaut R, Leproust S, et al. Effectiveness of prenatal treatment for congenital toxoplasmosis: a meta-analysis of individual patients' data. Lancet. 2007;369(9556):115-122.

4. Gras L, Wallon M, Pollak A, et al. Association between prenatal treatment and clinical manifestations of congenital toxoplasmosis in infancy: a cohort study in 13 European centres. Acta Paediatr. 2005;94(12):1721-1731.

5. Cortina-Borja M, Tan HK, Wallon M, et al. Prenatal treatment for serious neurological sequelae of congenital toxoplasmosis: an observational prospective cohort study. PLoS Med. 2010;7(10).

6. Koppe JG, Loewer-Sieger DH, de Roever-Bonnet H. Results of 20 -year follow-up of congenital toxoplasmosis. Lancet. 1986;1(8475): 254-256.

\section{Clinical Ophthalmology}

\section{Publish your work in this journal}

Clinical Ophthalmology is an international, peer-reviewed journal covering all subspecialties within ophthalmology. Key topics include: Optometry; Visual science; Pharmacology and drug therapy in eye diseases; Basic Sciences; Primary and Secondary eye care; Patient Safety and Quality of Care Improvements. This journal is indexed on Submit your manuscript here: http://www.dovepress.com/clinical-ophthalmology-journal
7. Wilson CB, Remington JS, Stagno S, Reynolds DW. Development of adverse sequelae in children born with subclinical congenital Toxoplasma infection. Pediatrics. 1980;66(5):767-774.

8. Berrébi A, Assouline C, Bessières MH, et al. Long-term outcome of children with congenital toxoplasmosis. Am J Obstet Gynecol. 2010;203(6):552. e1-e6.

9. Faucher B, Garcia-Meric P, Franck J, et al. Long-term ocular outcome in congenital toxoplasmosis: a prospective cohort of treated children. J Infect. 2012;64(1):104-109.

10. Kodjikian L, Wallon M, Fleury J, et al. Ocular manifestations in congenital toxoplasmosis. Graefes Arch Clin Exp Ophthalmol. 2006;244(1):14-21.

11. Tan HK, Schmidt D, Stanford M, et al. Risk of visual impairment in children with congenital toxoplasmic retinochoroiditis. Am J Ophthalmol. 2007;144(5):648-653.

12. Wallon M, Kodjikian L, Binquet C, et al. Long-term ocular prognosis in 327 children with congenital toxoplasmosis. Pediatrics. 2004;113(6):1567-1572.

13. Gilbert RE, Freeman K, Lago EG, et al. Ocular sequelae of congenital toxoplasmosis in Brazil compared with Europe. PLoS Negl Trop Dis. 2008;2(8):e277.

14. Diza E, Frantzidou F, Souliou E, Arvanitidou M, Gioula G, Antoniadis A. Seroprevalence of Toxoplasma gondii in northern Greece during the last 20 years. Clin Microbiol Infect. 2005;11(9):719-723.

15. Antoniou M, Tzouvali H, Sifakis S, et al. Incidence of toxoplasmosis in 5532 pregnant women in Crete, Greece: management of 185 cases at risk. Eur J Obstet Gynecol Reprod Biol. 2004;117(2):138-143.

16. Baka S, Makrakis E, Hassiakos D, Logginidis I, Meretaki S, Kouskouni E. Screening for Toxoplasma gondii, rubella virus and Cytomegalovirus in pregnant women. Clin Microbiol Infect. 2006;12 Suppl 4:873.

17. Alexandrou ME, Zagotzidou E, Voyatzi A, et al. A 4-year seroepidemiological screening for CMV, rubella, and Toxoplasma infections among women of child-bearing age. Clin Microbiol Infect. 2002; 8 Suppl 1):282.

18. Aptouramani M, Theodoridou M, Syrogiannopoulos G, et al. A dedicated surveillance network for congenital toxoplasmosis in Greece, 2006-2009: assessment of the results. BMC Public Health. 2012;12: 1019.

19. Bénard A, Petersen E, Salamon R, Chêne G, Gilbert R, Salmi LR. Survey of European programmes for the epidemiological surveillance of congenital toxoplasmosis. Euro Surveill. 2008;13(15).

20. Villena I, Ancelle T, Delmas C, et al. Congenital toxoplasmosis in France in 2007: first results from a national surveillance system. Euro Surveill. 2010;24:15(25).

21. Gilbert RE, Stanford MR. Is ocular toxoplasmosis caused by prenatal or postnatal infection? Br J Ophthalmol. 2000;84(2):224-226.

22. Burnett AJ, Shortt SG, Isaac-Renton J, King A, Werker D, Bowie WR. Multiple cases of acquired toxoplasmosis retinitis presenting in an outbreak. Ophthalmology. 1998;105(6):1032-1037.

23. Perkins ES. Ocular toxoplasmosis. Br J Ophthalmol. 1973;57(1): $1-17$.

24. Glasner PD, Silveira C, Kruszon-Moran D, et al. An unusually high prevalence of ocular toxoplasmosis in southern Brazil. Am J Ophthalmol. 1992;114(2):136-144.

25. Kijlstra A, Jongert E. Toxoplasma-safe meat: close to reality? Trends Parasitol. 2009;25(1):18-22.

PubMed Central and CAS, and is the official journal of The Society of Clinical Ophthalmology (SCO). The manuscript management system is completely online and includes a very quick and fair peer-review system, which is all easy to use. Visit http://www.dovepress.com/ testimonials.php to read real quotes from published authors. 